\title{
Approximate Solutions to Coupled Shear Walls on Fixed and Flexible Foundations
}

\author{
Rajesh Vuddandam ${ }^{1}$, Houssam Toutanji ${ }^{1} \&$ Richard Rodgers ${ }^{1}$ \\ ${ }^{1}$ Department of Civil and Environmental Engineering, University of Alabama in Huntsville, Huntsville, AL, USA \\ Correspondence: Rajesh Vuddandam, University of Alabama in Huntsville, Huntsville, AL 35899, USA. Tel: \\ 1-256-684-0323. E-mail: rajesh.vuddandam@uah.edu
}

Received: January 13, 2013

Accepted: February 21, 2013 Online Published: March 3, 2013

doi:10.5539/mas.v7n4p1

URL: http://dx.doi.org/10.5539/mas.v7n4p1

\begin{abstract}
In this paper, closed form approximate solutions to the equations of motion for coupled shear walls are developed using Ritz-Galerkin method. Hamilton's principle is used to derive the equations of motion. These equations and solutions were developed for two different cases, one for the coupled shear wall on fixed foundation and the other for coupled shear wall on flexible foundation. Through literature review, it is identified that previous studies addressed only the free vibration of coupled shear wall system without considering external load. The main focus of this paper is to develop equations of motion with external load applied to coupled shear walls on both fixed and flexible base using variational approach. Then cast equations of motion and corresponding boundary conditions into non-dimensional form. The solution of equations of motion is developed through the use of the Ritz-Galerkin technique. Thus attempts were made to develop equations of motion considering a driving force, $p(x, t)$ on the structure. By using selected shape functions for the longitudinal and lateral defelections, a matrix eigenvalue equation is derived for both cases yielding closed form approximate solution.
\end{abstract}

Keywords: coupled shear walls, blast load, dynamics, Ritz-Galerkin

\section{Introduction}

In tall building systems, reinforced concrete coupled shear walls are widely used to provide lateral resistance against the dynamic loads arising from earthquakes, wind and blast loads. Earlier investigations considered the effects of both fixed and flexible foundation to predict the stresses and deformation of coupled shear walls. The analysis of coupled shear wall systems may be approached from several directions. The particular approach selected by the structural engineer will depend upon the desired application and the design stage of the structure. If the need is for preliminary design analysis, it is more amenable to use approximate techniques. Now-a-days, it has become a standard in the design and analysis of coupled shear walls or shear wall systems to use the continuum medium technique. One benefit of this approach is that the differential equation developed, under the continuum approximation, will have a closed form solution.

The continuous medium method was first used by Chitty (1947) in the analysis of a cantilever composed of a series of parallel beams interconnected by cross bars. Chitty and Wan (1948) applied the technique to tall building structures under wind loads. Beck (1962) presented an approximate method of analysis where a continuous system replaced a discontinuous frame system, which took into account the shear deformation due to normal forces. Rosman (1964) developed an approximate method of analysis for the case of a concentrated load at the top of the structure using continuum approximation. Coull and Choudhury (1967) used the continuum approximation to develop curves useful for rapid evaluation of the stresses and maximum deflection in any system of coupled shear walls. Tso and Biswas (1973) used the continuum approach to address the deformations of the coupled shear walls subject to lateral loading. In their study the coupled shear walls were not restricted to be in plane. For the non-planar coupled shear walls, the loading becomes nonsymmetrical and torsion effects are introduced into the structure. Gluck (1973) used the continuum approach to address elasto-plastic analysis of coupled shear walls. Wang et al. (2005) used fourth order Sturm-Liouville differential equation, to determine first two periods of natural vibration of the buildings with uniform coupled shear walls.

Skattum (1971) made a study of the free vibrations of planar coupled shear walls by using the variational approach and assuming the spandrels can be replaced by a system of continuous laminae. Skattum method 
considered the effects of longitudinal motion in an approach, which keep the motion in the longitudinal direction of the wall as separate variables. Skattum's free vibration work was conducted under the assumption of fixed foundation. Mukherjee and Coull (1973) computed the free vibrations of coupled shear walls under the continuum assumption. Their work developed the dynamical equations for a fixed base using force moment equations. The equations of motion were transformed into one sixth order differential equation, which was solved using the Galerkin technique. Mukherjee and Coull (1974) later developed an approximate technique to compute the free vibrations of coupled shear walls on flexible bases.

The dynamics of coupled shear walls has not been addressed to near the degree as that of static loading. Most of the work has addressed only the free vibration analysis of the coupled shear wall system. Previous studies conducted free vibration analysis of coupled shear walls using continuum approach on fixed base (Mukherjee \& Coull, 1973) and discrete-continuous approach (Lee \& Choo, 1995). Discrete-continuous approach is later applied to stiffened coupled shear walls with fixed base (Kuang \& Chau, 1964) and flexible base (Kuang \& Chau, 1999). Having the free vibration analysis is very important to predicting the response of a coupled shear wall system to earthquake and wind loading, the development of the equation of motion with the load included, and then searching for solutions to these equations, has had little attention from researchers in tall buildings. This paper develops equations of motion with load included using a variational approach on both fixed and flexible foundation.

In this paper, the computation of the equations of motion for coupled shear walls will be developed under two separate conditions using a variational method. The first case (Case I) will proceed with the assumption that the foundation is fixed with there being no significant longitudinal or rotational kinetic energy in the system. The second case (Case II) will be a higher order theory where the flexibility of the foundation is not assumed fixed and the rotational and longitudinal kinetic energies are included as possibly a significant contribution to the dynamical system. Figure 1 provides an illustration of the general lateral loading of coupled shear walls.

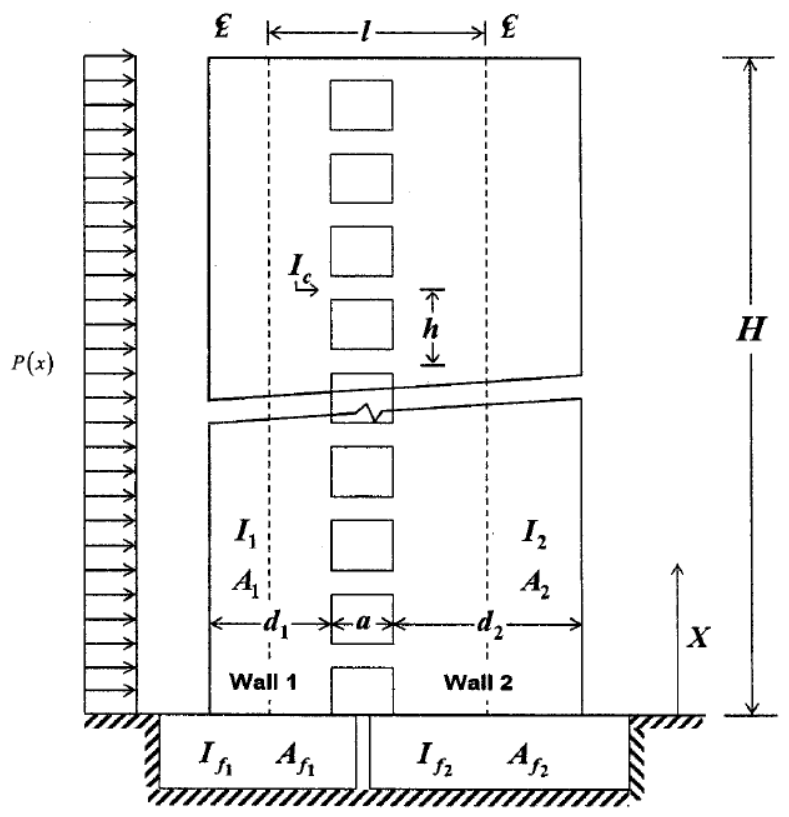

Figure 1. Laterally loaded coupled shear walls

The approach to both cases will be through the use of Hamilton's principle given by

$$
\delta \int_{t_{0}}^{t_{1}} L d t=0
$$

where $L$ is the Lagrangian of the structural system. $L$ is the total kinetic energy of the system minus the total systems potential energy. Hamilton's principle is stated as the actual motion, which takes place in a conservative dynamic system in the time interval between $\mathrm{t}_{0}$ and $\mathrm{t}_{1}$, provides a stationary value to the action integral, $I_{A}$, where

$$
I_{\mathrm{A}}=\int_{t_{0}}^{t_{1}} L d t
$$


that is, $\delta \mathrm{I}_{\mathrm{A}}=0$.

The shear wall system shown in Figure 1 will be analyzed by replacing the connecting beams by a uniform system of continuous lamina as shown in Figure 2. This approach is similar to that developed by Skattum (1971), except that he did not consider the case of coupled shear walls on flexible base.

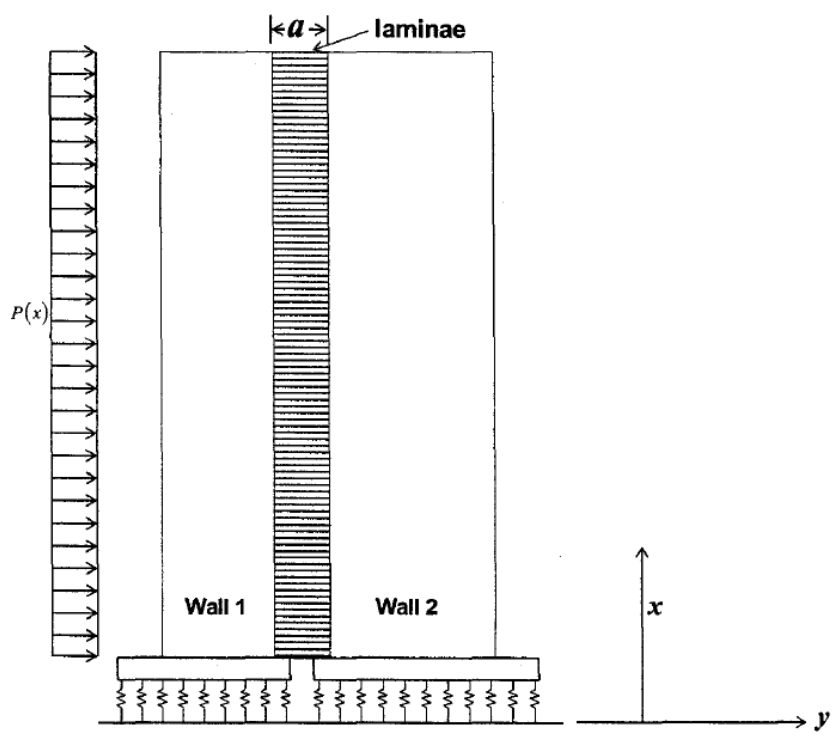

Figure 2. Coupled shear wall with beams replaced by a system of continuous laminae

It will be shown that the Hamilton's principle, or the variational method, applied to the first case will exactly reproduce the dynamical equation developed by Mukherjee and Coull (1973), which used a different approach to compute the free vibration state of coupled shear walls on a fixed foundation. Todevelop equations of motion, the total potential energy of the system for general case is given by

$$
V=V_{W}+V_{C}+V_{F} .
$$

In this equation $V_{W}$ is the total strain energy of the walls under bending and axial deformaton. $V_{C}$ is the strain energy in the connecting lamellae, and $V_{F}$ is the strain energy of the flexible foundation. The total potential energy of the system and kinetic energy of the systemfor both cases are shown in Table 1 and Table 2 respectively. In the case of coupled shear walls on a fixed foundation, rotational and longitudinal kinetic energies are neglected, whereas on a flexible foundation kinetic energy due to rotation $\left(T_{R}\right)$ and longitdinal $\left(T_{L}\right)$ motion of the wall is considered. The equation of the strain energy due to flexible foundation is provided by Mukherjee and Coull (1974).

Table 1. Total potential energy of the system $(V)$

$$
\begin{aligned}
& \text { Case I } \overbrace{\frac{E}{2}\left\{I \int_{0}^{H} y_{x x}^{2} d x+\frac{A_{1} A_{2}}{A} \int_{0}^{\mathrm{H}} u_{x}^{2} d x\right\}}^{V_{W}}+\overbrace{\frac{6 E I_{c}}{h a^{3}} \int_{0}^{H}\left(l y_{x}-u\right)^{2} d x}^{\nabla_{C}} \\
& \text { Case II } \overbrace{\frac{E}{2}\left\{I \int_{0}^{H} y_{x x}^{2} d x+\frac{A_{1} A_{2}}{A} \int_{0}^{\mathrm{H}} u_{x}^{2} d x\right\}}^{{ }_{V_{W}}}+\overbrace{\frac{6 E I_{c}}{h a^{3}} \int_{0}^{H}\left(l y_{x}-u\right)^{2} d x}^{V_{C}}+\overbrace{\left.\frac{1}{2}\left[K_{b} y_{x}^{2}+\frac{K_{a_{1}} K_{a_{2}}}{K_{a}} u^{2}\right]\right|_{x=0}}^{{ }_{F_{F}}}
\end{aligned}
$$


Table 2. Kinetic energy of the system $(T)$

$$
\begin{array}{ll}
\text { Case I } \frac{\rho}{2} \int_{0}^{H} A y_{t}^{2} d x & \frac{\rho}{\text { Case II }} \frac{\rho}{2} \int_{0}^{H} A y_{t}^{2} d x+\underbrace{\frac{\rho}{2} \int_{0}^{H} I y_{x t}^{2} d x}_{\left[T_{R}\right.}+\underbrace{\frac{\rho}{2} \int_{0}^{H} \frac{A_{1} A_{2}}{A} u_{t}^{2} d x}_{\left[T_{L}\right.}
\end{array}
$$

\section{Equations of Motion and Boundary Conditions}

\subsection{Coupled Shear Walls on Fixed Foundation (Case I)}

If $\delta \mathrm{W}_{\mathrm{nc}}$ is work done by non-conservative forces (external) and any conservative forces not considered in the Lagrangian L, Hamilton's principle with inclusion of $\delta \mathrm{W}_{\mathrm{nc}}$ is given by

$$
\int_{\mathrm{t}_{0}}^{\mathrm{t}_{1}} \delta \mathrm{Ldt}+\int_{\mathrm{t}_{0}}^{\mathrm{t}_{1}} \delta \mathrm{W}_{\mathrm{nc}} \mathrm{dt}=0
$$

The Lagrangian, $\mathrm{L}$ for coupled shear walls on fixed foundation is given by

$$
\begin{gathered}
T=\frac{\rho}{2} \int_{0}^{H} \mathrm{Ay}_{\mathrm{t}}^{2} \mathrm{dx} \\
V=\frac{\mathrm{E}}{2}\left\{\mathrm{I} \int_{0}^{H} \mathrm{y}_{\mathrm{xx}}^{2} \mathrm{dx}+\frac{\mathrm{A}_{1} \mathrm{~A}_{2}}{\mathrm{~A}} \int_{0}^{H} \mathrm{u}_{\mathrm{x}}^{2} \mathrm{dx}\right\}+\frac{6 \mathrm{EI}_{\mathrm{c}}}{\mathrm{ha}^{3}} \int_{0}^{H}\left(\mathrm{ly}_{\mathrm{x}}-\mathrm{u}\right)^{2} \mathrm{dx} \\
\delta \mathrm{L}=\int_{0}^{H}\left\{\rho \mathrm{Ay}_{\mathrm{t}} \delta \mathrm{y}_{\mathrm{t}}-\mathrm{EIy}_{\mathrm{xx}} \delta \mathrm{y}_{\mathrm{xx}}-\frac{\mathrm{EA}_{1} \mathrm{~A}_{2}}{\mathrm{~A}} \mathrm{u}_{\mathrm{x}} \delta \mathrm{u}_{\mathrm{x}}-\frac{12 \mathrm{EI}_{\mathrm{c}}}{\mathrm{ha}^{3}}\left(\mathrm{ly}_{\mathrm{x}}-\mathrm{u}\right) \delta\left(\mathrm{ly}_{\mathrm{x}}-\mathrm{u}\right)\right\} \mathrm{dx} \\
\delta \mathrm{W}_{\mathrm{nc}}=\int_{0}^{H}\{\mathrm{p}(\mathrm{x}, \mathrm{t}) \delta \mathrm{y}\} \mathrm{dx}
\end{gathered}
$$

Using and applying integration by parts, the Equation (3) developed from Hamilton's principle can be reduced to

$$
\begin{gathered}
E I y_{x x x x}-\frac{12 E I_{c}}{h a^{3}} l\left(l y_{x x}-u_{x}\right)+\rho A y_{t t}=p(x, t) \\
\frac{E A_{1} A_{2}}{A} u_{x x}+\frac{12 E I_{c}}{h a^{3}}\left(l y_{x}-u\right)=0
\end{gathered}
$$

These equations provide the equations of motion of the coupled shear wall system, case I, under the continuum approximation, on a fixed foundation with rotational and translational kinetic energies neglected. In these equations $\mathrm{u}$ is motion in the longitudinal direction and $\mathrm{y}$ is deflection in the lateral direction. The equations were not derived in this form by Mukherjee and Coull, rather presented a sixth order differential equation given by Equation (9), which has less ease to solve them by hand calculations.

$$
\text { EI } \frac{\partial^{6} y}{\partial x^{6}}-\operatorname{EI}^{\prime} \frac{\partial^{4} y}{\partial x^{4}}=-\rho^{\prime} \frac{\partial^{4} y}{\partial x^{2} \partial t^{2}}+\beta^{\prime} \rho^{\prime} \frac{\partial^{2} y}{\partial t^{2}}
$$

with $\rho^{\prime}$ being the mass per unit height, $\alpha^{\prime}=\frac{12 \mathrm{I}_{\mathrm{c}}}{\mathrm{ha}^{3}}\left(\frac{\mathrm{l}^{2}}{\mathrm{I}}+\frac{\mathrm{A}}{\mathrm{A}_{1} \mathrm{~A}_{2}}\right)$ and $\beta^{\prime}=\frac{12 \mathrm{I}_{\mathrm{c}}}{\mathrm{ha}^{3}} \frac{\mathrm{A}}{\mathrm{A}_{1} \mathrm{~A}_{2}}$.

The approach used in this paper (variational approach) is different from that of Mukherjee and Coull (1973) (force moment approach). Equation (7) and Equation (8) can be reduced to six order differential equation given by Mukherjee and Coull (1973) with the appropriate change of notion. $\rho$ in the Lagrangian is mass per unit volume whereas $\rho$ ' is mass per unit length in Mukherjee and Coull's equation. It should also be noted that 
Mukherjee and Coull did not address the dynamic response of the structure under loading. Their dynamic analysis only addressed the free vibration problem.

The boundary condition equations, which are produced from the Hamilton's principle approach, are determined from the remaining terms of the parts of integration, which are not used to develop the equations of motion. Collecting terms not used in the calculation of differential equations of motion yields boundary conditions as shown below

Moment at top EIy $\left._{\mathrm{xx}}\right|_{\mathrm{x}=\mathrm{H}, \mathrm{t}}=0$,

Rotation at foundation $\left.\mathrm{y}_{\mathrm{x}}\right|_{\mathrm{x}=0}=0$,

Shear and rotation at top $\left.\left[\operatorname{EIy}_{\mathrm{xxx}}-\frac{12 \mathrm{EI}_{\mathrm{c}}}{\mathrm{ha}^{3}} 1\left(\mathrm{ly}_{\mathrm{x}}-\mathrm{u}\right)\right]\right|_{\mathrm{x}=\mathrm{H}, \mathrm{t}}=0$,

and, strain at top $\left.\mathrm{u}_{\mathrm{x}}\right|_{\mathrm{x}=\mathrm{H}, \mathrm{t}}=0$.

\subsection{Coupled Shear Walls on Flexible Foundation (Case II)}

The additional part (due to strain energy of the elastic foundation and kinetic energies of rotational and longitudinal motions) to be added to the Lagrangian of case I, to have Lagrangian for case II is

$$
\mathrm{L}_{\text {additional part }}=\underbrace{\frac{\rho}{2} \int_{0}^{H} \mathrm{Iy}_{\mathrm{xt}}^{2} \mathrm{dx}}_{\mathrm{T}_{\mathrm{R}}}+\underbrace{\frac{\rho}{2} \int_{0}^{H} \frac{\mathrm{A}_{1} \mathrm{~A}_{2}}{\mathrm{~A}} \mathrm{u}_{\mathrm{t}}^{2} \mathrm{dx}}_{\mathrm{T}_{\mathrm{L}}}-\overbrace{}^{\left.\frac{1}{2}\left[\mathrm{~K}_{\mathrm{b}} \mathrm{y}_{\mathrm{x}}^{2}+\frac{\mathrm{K}_{\mathrm{a}_{1}} \mathrm{~K}_{\mathrm{a}_{2}}}{\mathrm{~K}_{\mathrm{a}}} \mathrm{u}^{2}\right]\right|_{\mathrm{x}=0}}
$$

For arbitrary $\delta y$ and $\delta u$, this added variation reduce the equations of motion for the coupled shear wall system on flexible bases with inclusion of rotational and longitudinal kinetic energy to as follows:

$$
\begin{gathered}
E I y_{x x x x}-\frac{12 E I_{c}}{h a^{3}} l\left(l y_{x x}-u_{x}\right)+\rho A y_{t t}-\rho I y_{x x t t}=p(x, t) \\
\frac{E A_{1} A_{2}}{A} u_{x x}-\frac{\rho A_{1} A_{2}}{A} u_{t t}+\frac{12 E I_{c}}{h a^{3}}\left(l y_{x}-u\right)=0
\end{gathered}
$$

These equations form a set of coupled transverse and longitudinal dynamical equations of the shear wall system. The displacements $y$ and $u$ are coupled in the equations of motion and such coupling will be seen in the calculation of boundary conditions. If the desire is to calculate the free vibrations, this may be accomplished by setting the driving force, $\mathrm{p}(\mathrm{x}, \mathrm{t})$ in Equation (11), equal to zero.

In this case, computation of the boundary conditions proceeds by combining the coefficients of remaining integral terms not used in the calculation of equations of motion. The natural boundary conditions from remaining terms can be written as

$$
\begin{gathered}
{\left.\left[\operatorname{EIy}_{\mathrm{xxx}}-\frac{12 \mathrm{EI}_{\mathrm{c}}}{\mathrm{ha}^{3}} \mathrm{l}\left(\mathrm{ly}_{\mathrm{x}}-\mathrm{u}\right)-\rho \mathrm{Iy}_{\mathrm{xtt}}\right]\right|_{\mathrm{x}=\mathrm{H}, \mathrm{t}}=0,} \\
\left.\mathrm{EIy}_{\mathrm{xx}}\right|_{\mathrm{x}=\mathrm{H}, \mathrm{t}}=0, \\
{\left.\left[\mathrm{EAu}_{\mathrm{x}}-\mathrm{K}_{\mathrm{a}} \mathrm{u}\right]\right|_{\mathrm{x}=0}=0,} \\
{\left.\left[\mathrm{EIy}_{\mathrm{xx}}-\mathrm{K}_{\mathrm{b}} \mathrm{y}_{\mathrm{x}}\right]\right|_{\mathrm{x}=0}=0,} \\
\left.\mathrm{u}_{\mathrm{x}}\right|_{\mathrm{x}=\mathrm{H}, \mathrm{t}}=0
\end{gathered}
$$


The forced boundary condition is

$$
\left.y_{x}\right|_{x=0, t}=0 .
$$

\section{Equations of Motion and Boundary Conditions into Non-dimensional}

\subsection{Coupled Shear Walls on Fixed Foundation}

In order to ease the calculations, it is advantageous to cast the equation of motion and boundary conditions into dimensionless form. To do this, let $y(x, t)=Y(x)(P \cos \omega t+Q \sin \omega t)$ and $u(x, t)=U(x)(P \cos \omega t+Q \sin \omega t)$. Substituting corresponding derivatives into Equation (7) and Equation (8), and setting $p(x, t)=0$, since free vibration is the concern, gives

$$
\begin{gathered}
E I Y_{x x x x}-\frac{12 E I_{c} l}{h a^{3}}\left(l Y_{x x}-U_{x}\right)-\rho A \omega^{2} Y=0 \\
\frac{E A_{1} A_{2}}{A} U_{x x}+\frac{12 E I_{c}}{h a^{3}}\left(l Y_{x}-U\right)=0
\end{gathered}
$$

These equations may be cast into non-dimensional form assuming $z=\frac{x}{H}, \Psi=\frac{Y}{H}, \Theta=\frac{U}{l}$. By using appropriate derivatives and chain rule, Equation (13) and (14) can be reduced into non-dimensional form as follows

$$
\begin{gathered}
\Psi^{I V}-\alpha\left(\Psi^{\prime \prime}-\Theta^{\prime}\right)-\lambda \Psi=0 \\
\beta \Psi^{\prime}+\left(\Theta^{\prime \prime}-\beta \Theta\right)=0
\end{gathered}
$$

where $\alpha=\frac{12 I_{c} l^{2} H^{2}}{I h a^{3}}, \lambda=\frac{\rho A \omega^{3} H^{4}}{E I}, \beta=\frac{12 A I_{c} H^{2}}{h a^{3} A_{1} A_{2}}$.

Also, transforming the boundary conditions into their non-dimensional form, gives

$$
\begin{gathered}
\left.\Psi^{\prime \prime}\right|_{z=1, t}=0, \\
{\left.\left[\Psi^{\prime \prime \prime}-\alpha\left(\Psi^{\prime}-\Theta\right)\right]\right|_{z=1, t}=0,} \\
\left.\Psi^{\prime}\right|_{z=0, t}=0, \\
\left.\Theta^{\prime}\right|_{z=1, t}=0 . \\
\left.\Psi\right|_{z=0, t}=0, \\
\left.\Theta\right|_{z=0, t}=0 .
\end{gathered}
$$

\subsection{Coupled Shear Walls on Flexible Foundation}

By using the expressions for $y, u$ and derivatives $y_{x}, y_{x x}, y_{t t}, y_{x x x x}, u_{x}, u_{x x}$ used in case I with the additional derivatives given by $y_{x x t t}=-Y_{x x} \omega^{2}(P \cos \omega t+Q \sin \omega t)$ and $u_{t t}=-U \omega^{2}(P \cos \omega t+Q \sin \omega t)$, Equation (11) and Equation (12) becomes

$$
Y_{x x x x}-\frac{12 I_{c} l}{I h a^{3}}\left(l Y_{x x}-U_{x}\right)-\frac{\rho A \omega^{2}}{E I} Y+\frac{\rho I \omega^{2}}{E I} Y_{x x}=0
$$




$$
\frac{E A_{1} A_{2}}{A} u_{x x}-\frac{\rho A_{1} A_{2}}{A} u_{t t}+\frac{12 E I_{c}}{h a^{3}}\left(l y_{x}-u\right)=0
$$

Again use is made of the relations $z=\frac{x}{H}, \Psi=\frac{Y}{H}$, and $\Theta=\frac{U}{l}$, with the derivatives and transformations being the same as in case I. With the rearrangement of terms and substitution of the derivatives and transformations computed in case I, Equation (23) and Equation (24) now becomes

$$
\begin{gathered}
\Psi^{I V}-\alpha\left(\Psi^{\prime \prime}-\Theta^{\prime}\right)=\lambda\left(\Psi-Y_{r} \Psi^{\prime \prime}\right) \\
-\beta \Psi^{\prime}-\left(\Theta^{\prime \prime}-\beta \Theta\right)=\lambda Y_{l} \Theta
\end{gathered}
$$

where $\alpha=\frac{12 I_{c} l^{2} H^{2}}{I h a^{3}}, \lambda=\frac{\rho A \omega^{3} H^{4}}{E I}, \beta=\frac{12 A I_{c} H^{2}}{h a^{3} A_{1} A_{2}}, Y_{r}=Y_{l}=\frac{I}{A H^{2}}$.

Also, transforming the boundary conditions into their non-dimensional form, gives

$$
\begin{gathered}
{\left.\left[\Psi^{\prime \prime \prime}-\alpha\left(\Psi^{\prime}-\Theta\right)+\lambda Y_{r} \Psi^{\prime}\right]\right|_{z=1, t}=0,} \\
\left.\Psi^{\prime \prime}\right|_{z=1, t}=0 \\
{\left.\left[\Theta-S_{a} \Theta^{\prime}\right]\right|_{z=0, t}=0} \\
{\left.\left[\Psi^{\prime}-S_{b} \Psi^{\prime \prime}\right]\right|_{z=0, t}=0} \\
\left.\Theta^{\prime}\right|_{z=1, t}=0
\end{gathered}
$$

where $S_{a}=\frac{E A}{K_{a} H}, S_{b}=\frac{E I}{K_{b} H}$.

The case II equations of motion will reduce to the case I equation when $Y_{r}=Y_{l}=\frac{I}{A H^{2}}$ is set to zero, where $Y_{r}, Y_{l}$ is equivalent to the rotational and kinetic energies of the system. Also, setting $Y_{r}=0$ in Equation (27), $S_{a}=0$ in Equation (29) and $S_{b}=0$ in Equation (30) will reproduce the case I boundary conditions (Equation (18), Equation (22) and Equation (19)).

Since $S_{a}=\frac{E A}{K_{a} H}$ and $S_{b}=\frac{E I}{K_{b} H}$ occur when $K_{a}$ and $K_{b}$ are infinite, which occurs when the foundation is fixed, setting these parameters equal to zero in the boundary conditions, will, along with the vanishing of parameters listed above, reproduce the case I boundary conditions.

\section{Eigen Value Equations Using Ritz-Galerkin Technique}

\subsection{Coupled Shear Walls on Fixed Foundation}

Ritz-Galerkin technique is used to solve the differential equations of motion. Mukherjee and Coull (1973) used this method in their solution to free vibration problems for coupled shear walls on a flexible base as well as in solutions to equations of free vibration, originating in other types of tall structures.

In the Ritz-Galerkin technique the two shape functions $\Psi$ and $\Theta$ are approximated by a linear combination of suitable co-ordinate functions. These functions are given as 


$$
\Psi=\sum_{\mathrm{j}=1}^{\mathrm{n}} \mathrm{c}_{\mathrm{j}} \mathrm{v}_{\mathrm{j}}
$$

and

$$
\Theta=\sum_{j=1}^{n} g_{j} w_{j}
$$

where $c_{j}$ and $g_{j}$ are chosen to satisfy all the uncoupled boundary conditions. The $c_{j}$ and $g_{j}$ are generalized co-ordinates, which are not a function of time, which will be determined by the varational process. The shape functions will be substituted into the non-dimensional equations of motion and boundary conditions. The substitution of these approximate functions will not provide exact satisfaction of the differential equations and coupled boundary conditions. The difference between the exact value and the approximate value is referred to as a residual.

The derivative of order $\mathrm{k}$ of the shape functions will be represented in the form given by

$$
\Psi^{k}=\sum_{k=1}^{n} c_{j} v_{j}^{k}
$$

and

$$
\Theta^{\mathrm{k}}=\sum_{\mathrm{k}=1}^{\mathrm{n}} \mathrm{g}_{\mathrm{j}} \mathrm{w}_{\mathrm{j}}^{\mathrm{k}}
$$

substituting these derivatives into the non-dimensional form of the equations of motion given in Equation (15) and Equation (16) will give the residuals for this system.

Using the Equation (15), leads to the residual given by

$$
\mathrm{R}_{1}^{\mathrm{I}}=\sum_{\mathrm{j}=1}^{\mathrm{n}} \mathrm{c}_{\mathrm{j}}\left(\mathrm{v}_{\mathrm{j}}^{\mathrm{IV}}-\alpha \mathrm{v}_{\mathrm{j}}^{\prime \prime}-\lambda \mathrm{v}_{\mathrm{j}}\right)-\sum_{\mathrm{j}=1}^{\mathrm{n}} \alpha \mathrm{g}_{\mathrm{j}} \mathrm{w}_{\mathrm{j}}^{\prime}
$$

substituting the shape functions and the appropriate derivatives into the coupled boundary conditions given by Equation (23), provides another residual given by

$$
R_{2}^{I}=-\left.\left[\sum_{j=1}^{n} c_{j}\left[v_{j}^{\prime \prime \prime}-\alpha v_{j}^{\prime}\right]+\sum_{j=1}^{n} \alpha g_{j} w_{j}\right]\right|_{z=1}
$$

Using the Equation (21), leads to third residual given by

$$
\mathrm{R}_{3}^{\mathrm{I}}=\beta \sum_{\mathrm{j}=1}^{\mathrm{n}} \mathrm{c}_{\mathrm{j}} \mathrm{v}_{\mathrm{j}}^{\prime}+\sum_{\mathrm{j}=1}^{\mathrm{n}} \mathrm{g}_{\mathrm{j}}\left(\mathrm{w}_{\mathrm{j}}^{\prime \prime}-\beta \mathrm{w}_{\mathrm{j}}\right)
$$

Mukherjee and Coull (1973) take the approach that residuals occurring in tall structures represent residual forces .With this understanding the residuals $R_{1}^{I}, R_{2}^{I}$ and $R_{3}^{I}$ for case I are then described as $R_{1}^{I}$ being a residual force distributed transversely within domain, $R_{2}^{I}$ is a concentrated residual force acting at the free boundary, and $R_{3}^{I}$ is one distributed longitudinally within the domain. The analysis requires that the virtual work performed by these residual forces during the virtual displacements $\delta c_{i} v_{i}$ and $\delta g_{i} w_{i}$, must vanish within the domain and at the boundaries. The necessary conditions which must be satisfied are given by

$$
\begin{gathered}
\int_{0}^{1} R_{1}^{\mathrm{I}} \mathrm{v}_{\mathrm{i}} \mathrm{dz}+\left.\left(\mathrm{R}_{2}^{\mathrm{I}} \mathrm{V}_{\mathrm{i}}\right)\right|_{\mathrm{z}=1}=0 \\
\int_{0}^{1} \mathrm{R}_{3}^{\mathrm{I}} \mathrm{W}_{\mathrm{i}} \mathrm{dz}=0, \text { for all } \mathrm{i}=1,2, \ldots, \mathrm{n}
\end{gathered}
$$

Substituting residuals $R_{1}^{I}$ and $R_{2}^{I}$ in Equation (39), leads to

$$
\sum_{j=1}^{n} c_{j} \overbrace{\left\{\int_{0}^{1} v_{i}\left\{v_{j}^{I V}-\alpha v_{j}^{\prime \prime}\right\} d z-\left.v_{i}\left\{v_{j}^{\prime \prime \prime}-\alpha v_{j}^{\prime}\right\}\right|_{z=1}\right\}}^{a_{i j}^{1}}+\alpha \sum_{j=1}^{n} g_{j} \overbrace{\left\{\int_{0}^{1} v_{i} w_{j}^{\prime} d z-\left.\left(v_{i} w_{j}\right)\right|_{z=1}\right\}}^{b}=\lambda \sum_{j=1}^{n} c_{j} \overbrace{\int_{0}^{1} v_{i j}}^{d_{i j}^{1} v_{j} d z}
$$

This equation provides a set of matrix values that are given by 


$$
\begin{gathered}
\mathrm{a}_{\mathrm{ij}}^{\mathrm{I}}=\int_{0}^{1}\left\{\mathrm{v}_{\mathrm{i}} \mathrm{v}_{\mathrm{j}}^{\mathrm{IV}}-\alpha \mathrm{v}_{\mathrm{i}} \mathrm{v}_{\mathrm{j}}^{\mathrm{\prime}}\right\} d \mathrm{dz}-\left.\left\{\mathrm{v}_{\mathrm{i}} \mathrm{v}_{\mathrm{j}}^{\prime \prime \prime}-\alpha \mathrm{v}_{\mathrm{i}} \mathrm{v}_{\mathrm{j}}^{\prime}\right\}\right|_{\mathrm{z}=1} \\
\mathrm{~b}_{\mathrm{ij}}^{\mathrm{I}}=\int_{0}^{1} \mathrm{i}_{\mathrm{i}}^{\prime} \mathrm{w} \mathrm{dz}-\left(\mathrm{v}_{\mathrm{i}} \mathrm{w}_{\mathrm{j}}\right) \mid \mathrm{v}_{\mathrm{z}=1} \\
\mathrm{~d}_{\mathrm{ij}}^{\mathrm{I}}=\int_{0}^{1} \mathrm{v}_{\mathrm{i}} \mathrm{v}_{\mathrm{j}} \mathrm{dz}
\end{gathered}
$$

With the available boundary conditions and using integration by parts, Equation (42), Equation (43) and Equation (44) can be further reduced.

Using the computed matrix elements, Equation (41) may now be written as

$$
\sum_{j=1}^{n} c_{j} a_{i j}^{I}+\alpha \sum_{j=1}^{n} g_{j} b_{i j}^{I}=\lambda \sum_{j=1}^{n} c_{j} d_{i j}^{I}, \text { for } i=1,2, \ldots n .
$$

This equation may now be written using matrix notation as

$$
{ }_{\bar{A}}^{I} \bar{C}+\alpha \overline{\bar{B}}^{I} \bar{G}=\lambda \overline{\bar{D}}^{I} \bar{C}
$$

where the double overbar is for a matrix and the single overbar is used to indicate a vector. The vectors $\bar{C}$ and $\bar{G}$, have components given by $c_{j}$ and $g_{j}$ in the matrix equation in Equation (45).

Similarly, substituting residual $R_{3}^{I}$ in Equation (40), reduces to the form

$$
\sum_{j=1}^{n} \beta c_{j} b_{i j}^{* I}+\sum_{j=1}^{n} g_{j} a_{i j}^{* I}=0, \text { for } i=1,2, \ldots, n \text {. }
$$

where

$$
\begin{gathered}
a_{i j}^{* I}=\int_{0}^{1} w_{j}^{\prime} w_{i}^{\prime} d z+\beta \int_{0}^{1} w_{j} w_{i} d z \\
b_{i j}^{* I}=-\int_{0}^{1} v_{j}^{\prime} w_{i} d z
\end{gathered}
$$

Further, Equation (46) may be cast into the matrix form as

$$
\beta \bar{B}^{* I} \bar{C}+\overline{\bar{A}}^{* I} \bar{G}=0
$$

Thus results of Ritz-Galerkin method for case I are given by the set of matrix equations

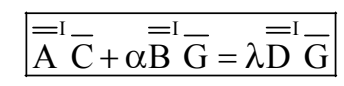

and

$$
\beta \overline{\overline{\mathrm{B}}}^{* \mathrm{I}} \overline{\mathrm{C}}+\overline{\overline{\mathrm{A}}}^{* \mathrm{I}} \overline{\mathrm{G}}=\lambda \overline{\overline{\mathrm{O}}} \overline{\mathrm{G}}
$$

In the Equation (50), the matrix given by $\overline{\bar{O}}$, is the matrix with entries being zero in all its elements.

\subsection{Coupled Shear Walls on Flexible Foundation}

In order to obtain solution to the equation of motion of case II, approach which was used in the case I, will again be used. Substituting Equation (34) and Equation (35) into Equation (25) and Equation (26), leads to the residuals given by

$$
\begin{aligned}
& R_{1}^{I I}=\sum_{j=1}^{n} c_{j}\left(v_{j}^{I V}-\alpha v_{j}^{\prime \prime}-\lambda\left(v_{j}-Y_{r} v_{j}^{\prime \prime}\right)\right)-\sum_{j=1}^{n} \alpha g_{j} w_{j}^{\prime}, \\
& R_{2}^{I I I}=-\left.\left[\sum_{j=1}^{n} c_{j}\left[v_{j}^{\prime \prime \prime}-\alpha v_{j}^{\prime}-\lambda Y_{r} v_{j}^{\prime}\right]+\sum_{j=1}^{n} \alpha g_{j} w_{j}\right]\right|_{z=1},
\end{aligned}
$$




$$
\mathrm{R}_{3}^{\mathrm{II}}=\beta \sum_{\mathrm{j}=1}^{\mathrm{n}} \mathrm{c}_{\mathrm{j}} \mathrm{v}_{\mathrm{j}}^{\prime}+\sum_{\mathrm{j}=1}^{\mathrm{n}} \mathrm{g}_{\mathrm{j}}\left\{\left(\mathrm{w}_{\mathrm{j}}^{\prime \prime}-\beta \mathrm{w}_{\mathrm{j}}\right)+\lambda \mathrm{Y}_{1} \mathrm{w}_{\mathrm{j}}\right\} .
$$

In case II, it is also required that the virtual work performed by the residual forces during the virtual displacements $\delta c_{i} v_{i}$ and $\delta g_{i} w_{i}$ must vanish. The necessary conditions which must be satisfied are given by

$$
\int_{0}^{1} \mathrm{R}_{1}^{\mathrm{II}} \mathrm{v}_{\mathrm{i}} \mathrm{dz}+\left.\left(\mathrm{R}_{2}^{\mathrm{II}} \mathrm{v}_{\mathrm{i}}\right)\right|_{\mathrm{z}=1}=0
$$

and

$$
\int_{0}^{1} R_{3}^{\text {II }} w_{i} d z=0, \text { for all } i=1,2, \ldots, n .
$$

Substituting residuals $R_{1}^{I I}$ and $R_{2}^{I I}$ in Equation (54), reduces to form

$$
\sum_{j=1}^{n} c_{j} a_{i j}^{I I}+\alpha \sum_{j=1}^{n} g_{j} b_{i j}^{I I}=\lambda \sum_{j=1}^{n} c_{j} d_{i j}^{I I j} \text {, for } i=1,2, \ldots, n
$$

where

$$
\begin{gathered}
a_{i j}^{I I I}=\int_{0}^{1} v_{i}^{\prime \prime} v_{j}^{\prime \prime} d z+\alpha \int_{0}^{1} v_{i}^{\prime} v_{j}^{\prime} d z+\left.S_{b}\left[v_{i}^{\prime \prime} v_{j}^{\prime \prime}\right]\right|_{z=0} \\
b_{i j}^{I I I}=-\int_{0}^{1} v_{i}^{\prime} w_{j} d z \\
d_{i j}^{I I I}=\int_{0}^{1} v_{i} v_{j} d z+Y_{r} \int_{0}^{1} v_{i}^{\prime} v_{j}^{\prime} d z
\end{gathered}
$$

Equation (56) may now be written using matrix notation as

$$
{ }_{\bar{A}}^{I I} \bar{C}+\alpha \bar{B}^{I I} \bar{G}=\lambda \overline{\bar{D}}^{I I} \bar{C}
$$

Similarly, substituting residual $R_{3}^{I I}$ in Equation (55), reduces to the form

$$
\sum_{\mathrm{j}=1}^{\mathrm{n}} \beta \mathrm{c}_{\mathrm{j}} \mathrm{b}_{\mathrm{ij}}^{* \text { II }}+\sum_{\mathrm{j}=1}^{\mathrm{n}} \mathrm{g}_{\mathrm{j}} \mathrm{a}_{\mathrm{ij}} \mathrm{II}=\lambda \sum_{\mathrm{j}=1}^{\mathrm{n}} \mathrm{g}_{\mathrm{j}} \mathrm{d}_{\mathrm{ij}}^{* \text { III }}, \text { for } \mathrm{i}=1,2, \ldots, \mathrm{n} \text {. }
$$

where

$$
\begin{aligned}
\mathrm{a}_{\mathrm{ij}}^{*} \mathrm{*II}^{\mathrm{II}}=\int_{0}^{1} \mathrm{w}_{\mathrm{j}}^{\prime} \mathrm{w}_{\mathrm{i}}^{\prime} \mathrm{dz}+ & \beta \int_{0}^{1} \mathrm{w}_{\mathrm{j}} \mathrm{w}_{\mathrm{i}} \mathrm{dz}+\left.\mathrm{S}_{\mathrm{a}}\left[\mathrm{w}_{\mathrm{i}}^{\prime} \mathrm{w}_{\mathrm{j}}^{\prime}\right]\right|_{z=0} \\
\mathrm{~b}_{\mathrm{ij}}^{* \text { II }}= & -\int_{0}^{1} \mathrm{v}_{\mathrm{j}} \mathrm{w}_{\mathrm{i}} \mathrm{dz} \\
\mathrm{d}_{\mathrm{ij}}^{*} \mathrm{II} & =\mathrm{Y}_{1} \int_{0}^{1} \mathrm{w}_{\mathrm{i}} \mathrm{w}_{\mathrm{j}} \mathrm{dz}
\end{aligned}
$$

Further, Equation (60) may be cast into the matrix form as

$$
\beta \overline{\bar{B}}^{* I I} \bar{C}+\overline{\bar{A}}^{*} \bar{G} \bar{G}=\lambda \overline{\bar{D}}^{* I I} \bar{G}
$$

Results of Ritz-Galerkin method for case II given by the set of matrix equations

$$
\overline{\bar{A}}^{I I} \bar{C}+\alpha \overline{\bar{B}}^{I I} \bar{G}=\lambda \overline{\bar{D}}^{I I} \bar{G}
$$

and

$$
\beta \overline{\bar{B}}^{* I I} \bar{C}+\overline{\bar{A}}^{*} I I \bar{G}=\lambda \overline{\bar{D}}^{*} \bar{G}
$$

The two matrix equations for both case I and case II may be combined to yield one matrix eigenvalue equation for each case and is given by 


$$
\begin{aligned}
& {\left[\begin{array}{cc}
\overline{\bar{A}}^{I} & \overline{\bar{B}}^{I} \\
\bar{\alpha} & \\
\overline{\bar{B}}^{* I} & \frac{\overline{\bar{A}}^{*} I}{\beta}
\end{array}\right]\left[\begin{array}{l}
\overline{\mathrm{C}} \\
\overline{\mathrm{G}}
\end{array}\right]=\lambda\left[\begin{array}{c}
\overline{\bar{D}}^{I} \\
\frac{\bar{O}}{\alpha} \\
\overline{\bar{O}} \\
\bar{O}
\end{array}\right]\left[\begin{array}{l}
\overline{\mathrm{C}} \\
\overline{\mathrm{G}}
\end{array}\right] \text { (for case I) }} \\
& {\left[\begin{array}{cc}
\overline{\bar{A}}^{I I} & \overline{\bar{B}}^{I I} \\
\alpha & \\
\overline{\bar{B}}^{* I I} & \frac{\overline{\bar{A}}^{*} I}{\beta}
\end{array}\right]\left[\begin{array}{l}
\overline{\mathrm{C}} \\
\overline{\mathrm{G}}
\end{array}\right]=\lambda\left[\begin{array}{cc}
\overline{\bar{D}} & \overline{\bar{O}} \\
\alpha & \\
\overline{\bar{O}} & \frac{\overline{\bar{D}}}{\beta}
\end{array}\right]\left[\begin{array}{l}
\overline{\mathrm{C}} \\
\overline{\mathrm{G}}
\end{array}\right] \text { (for case II) }}
\end{aligned}
$$

\section{Closed Form Approximate Solutions}

To provide solutions for the free and force driven coupled shear wall system, a particular set of shape functions are considered and is given by Equation (34) and Equation (35). The functions $v_{i}$ and $w_{i}$ in Equation (34) and Equation (35) respectively must be selected to satisfy the boundary conditions presented in each case. Mukherjee and Coull (1974) have approached several different structural systems where the equations of motion have been approximated by shape functions which satisfy the particular system under analysis. In their free vibration calculation for coupled shear walls, Mukherjee and Coull (1973) provide functions, which satisfy both cases of this paper. Thus to compute matrix coefficients, the shape functions developed by them will be used and is given by

$$
\begin{gathered}
\mathrm{v}_{\mathrm{i}}=\mathrm{l}_{\mathrm{i}} \mathrm{z}+\mathrm{m}_{\mathrm{i}} \mathrm{z}^{2}+\mathrm{n}_{\mathrm{i}} \mathrm{z}^{3}+\sin \frac{\mathrm{p}_{\mathrm{i}} \pi \mathrm{z}}{2} \\
\mathrm{w}_{\mathrm{i}}=\sin \mathrm{q}_{\mathrm{i}} \mathrm{z}+\mathrm{r}_{\mathrm{i}} \cos \mathrm{q}_{\mathrm{i}} \mathrm{z}
\end{gathered}
$$

where $p_{i}=1,3,5, \ldots,(2 \mathrm{i}-1)$, for all $i=1,2,3, \ldots, \mathrm{n}$.

The functions of Equation (68) have been chosen because they represent the deflection functions of a simple cantilever beam under sinusoidal loading. Equation (69) functions are used due to their representing of the mode shapes for free longitudinal vibration of a prismatic bar. The functions $v_{i}$ and $w_{i}$ must satisfy the boundary conditions of the functions they have been selected to represent, that is, the boundary conditions of $\Psi$ and $\Theta$, which are in the non-dimensional representation of the equations of motion. In order to solve the eigenvalue equations, the values of $r_{i}, q_{i}, l_{i}, m_{i}, n_{i}$ must be computed. These values will vary depending upon the foundation conditions, with additional values needing to be computed as the degrees of freedom, which produce additional shape functions and higher vibration modes, are increased.

\subsection{Coupled Shear Walls on Fixed Foundation}

For case I, the conditions on $\Psi$ given by Equation (17), Equation (18) and Equation (19) leads to conditions

$$
\left.\mathrm{v}_{\mathrm{i}}^{\prime \prime}\right|_{\mathrm{z}=1}=0,\left.\mathrm{v}_{\mathrm{i}}^{\prime}\right|_{\mathrm{z}=0}=0,\left.\left[\mathrm{v}_{\mathrm{i}}^{\prime \prime \prime}-\alpha\left(\mathrm{v}_{\mathrm{i}}^{\prime}-\mathrm{w}_{\mathrm{i}}\right)\right]\right|_{\mathrm{z}=1, \mathrm{t}}=0 .
$$

and conditions on $\Theta$ given by Equation (20) and Equation (22) leads to conditions,

$$
\left.\mathrm{w}_{\mathrm{i}}^{\prime}\right|_{\mathrm{z}=1}=0,\left.\quad \mathrm{w}_{\mathrm{i}}\right|_{\mathrm{z}=0}=0 .
$$

Using the above conditions, the coefficients for coordinate functions in the shape function expansion can be computed and is given by

$$
\begin{gathered}
l_{i}=-\frac{p_{i} \pi}{2} \\
n_{i}=\left[\left(\frac{p_{i} \pi}{2}\right)^{2} \sin \frac{p_{i} \pi}{2}-\sin \frac{p_{i} \pi}{2}-\frac{p_{i} \pi}{2}\right] /\left[\frac{6-3 \alpha}{\alpha}+6\right],
\end{gathered}
$$




$$
\begin{gathered}
m_{i}=-3 n_{i}+\frac{1}{2}\left(\frac{p_{i} \pi}{2}\right)^{2} \sin \frac{p_{i} \pi}{2} \text { and } \\
q_{i}=(2 i-1) \frac{\pi}{2}=\frac{p_{i} \pi}{2} \text { with } \mathrm{r}_{\mathrm{i}}=0 .
\end{gathered}
$$

With the chosen shape functions and with the solutions of the coefficients in these shape functions, matrix coefficients in case I given by Equation (42), Equation (43), Equation (44), Equation (47) and Equation (48), can be computed by evaluating integrals. These integrals require long computations; as such final results for matrix coefficients are given below.

$$
\begin{aligned}
& a_{i j}^{I}= 4 m_{i} m_{j}+6\left(m_{i} n_{j}+m_{j} n_{i}\right)+12 n_{i} n_{j}-\pi\left(p_{i} m_{j}+p_{j} m_{i}\right)-6\left[n_{i} \sin p_{j} \frac{\pi}{2}+n_{j} \sin p_{i} \frac{\pi}{2}\right] \\
&+\delta_{i j} \frac{1}{2}\left[\frac{p_{i} \pi}{2}\right]^{4}+\alpha\left(\begin{array}{l}
\left.l_{i} l_{j}+\left(m_{i} l_{j}+m_{j} l_{i}\right)+\left(n_{i} l_{j}+n_{j} l_{i}\right)+\frac{4}{3} m_{i} m_{j}+\frac{3}{2}\left(m_{i} n_{j}+m_{j} n_{i}\right)+\frac{9}{5} n_{i} n_{j}\right) \\
+\left[l_{i} \sin \frac{p_{j} \pi}{2}+l_{j} \sin \frac{p_{i} \pi}{2}\right]
\end{array}\right. \\
&+\alpha\left(\frac{4}{\pi}\left\{\frac{m_{i}}{p_{j}}\left[p_{j} \frac{\pi}{2} \sin \left[\frac{p_{j} \pi}{2}\right]-1\right]+\frac{m_{j}}{p_{i}}\left[p_{i} \frac{\pi}{2} \sin \left[\frac{p_{i} \pi}{2}\right]-1\right]\right\}+\right. \\
&\left.\frac{12}{\pi^{2}}\left\{\frac{n_{i}}{p_{j}^{2}}\left[\frac{1}{4} p_{j}^{2} \pi^{2}-2\right] \sin \frac{p_{j} \pi}{2}+\frac{n_{j}}{p_{i}^{2}}\left[\frac{1}{4} p_{i}^{2} \pi^{2}-2\right] \sin \frac{p_{i} \pi}{2}\right\}+\delta_{i j} \frac{1}{2}\left[\frac{p_{i} \pi}{2}\right]^{2}\right]
\end{aligned}
$$

Where $\delta_{i j}=\left\{\begin{array}{l}1, \text { if } i \neq j \\ 0, \text { if } i=j\end{array}\right.$

$$
b_{i j}^{I}=-\left(\begin{array}{l}
\frac{2 l_{i}}{p_{j} \pi}+\frac{8 m_{i}}{\pi^{2} p_{j}^{2}} \sin \frac{p_{j} \pi}{2}+3 n_{i}\left[\left[\frac{8}{p_{j}^{2} \pi^{2}} \sin \frac{p_{j} \pi}{2}-\frac{16}{p_{j}^{3} \pi^{3}}\right]\right]+\frac{1}{4}\left[1-\cos p_{i} \pi\right] \\
-\frac{1}{4}(i \neq j) p_{i}\left[\frac{1}{\left(p_{i}-p_{j}\right)}-\frac{1}{\left(p_{i}+p_{j}\right)}\right]
\end{array}\right)
$$

where the notation $\mathrm{i} \neq \mathrm{j}$ has the logical meaning, given by $\mathrm{i} \neq \mathrm{j}=\left\{\begin{array}{l}1, \text { if true } \\ 0 \text {, if false }\end{array}\right.$

$$
\begin{aligned}
d_{i j}^{I}= & \frac{1}{3} l_{i} l_{j}+\frac{1}{4}\left(m_{i} l_{j}+m_{j} l_{i}\right)+\frac{1}{5}\left(n_{i} l_{j}+n_{j} l_{i}+m_{i} m_{j}\right)+\frac{1}{6}\left(m_{i} n_{j}+m_{j} n_{i}\right)+\frac{1}{7} n_{i} n_{j} \\
& +\left[\frac{2}{\pi}\right]^{2}\left\{\frac{l_{i}}{p_{j}^{2}} \sin \frac{p_{j} \pi}{2}+\frac{l_{j}}{p_{i}^{2}} \sin \frac{p_{i} \pi}{2}\right\}+2\left[\frac{2}{\pi}\right]^{2}\left\{\frac{m_{i}}{p_{j}^{3}}\left[\frac{p_{j} \pi}{2} \sin \left[\frac{p_{j} \pi}{2}\right]-1\right]+\frac{m_{j}}{p_{i}^{3}}\left[\frac{p_{i} \pi}{2} \sin \left[\frac{p_{j} \pi}{2}\right]-1\right]\right\} \\
& +3\left[\frac{2}{\pi}\right]^{4}\left\{\frac{n_{i}}{p_{j}^{4}}\left[\left[\frac{1}{4} p_{i}^{2} \pi^{2}-2\right] \sin \frac{p_{j} \pi}{2}\right]+\frac{n_{j}}{p_{i}^{4}}\left[\left[\frac{1}{4} p_{i}^{2} \pi^{2}-2\right] \sin \frac{p_{i} \pi}{2}\right]\right\}+\frac{1}{2} \delta_{i j} \\
& a_{i j}^{* I}=\frac{\pi}{2} \frac{p_{i} p_{j}}{2}\left[\frac{\sin \left(p_{i}-p_{j}\right) \frac{\pi}{2}}{\left(p_{i}-p_{j}\right)}+\frac{\left.\sin \left(p_{i}+p_{j}\right) \frac{\pi}{2}\right]+\frac{\beta}{\pi}\left[\frac{\sin \left(p_{i}-p_{j}\right) \frac{\pi}{2}}{\left(p_{i}+p_{j}\right)}-\frac{\sin \left(p_{i}+p_{j}\right) \frac{\pi}{2}}{\left(p_{i}-p_{j}\right)}\right]}{b_{i j}^{* I}=\left[p_{j}\right)}\right]
\end{aligned}
$$


It is to be noted that results of matrix coefficients in case I, may be confirmed by comparing to results of Mukherjee and Coull (1974), who have supplied their results, for the free vibration case.

\subsection{Coupled Shear Walls on Flexible Foundation}

For case II, the conditions on $\Psi$ given by Equation (27), Equation (28) and Equation (30) leads to conditions

$$
\left[\mathrm{v}_{\mathrm{i}}^{\prime \prime \prime}-\alpha\left(\mathrm{v}_{\mathrm{i}}^{\prime}-\mathrm{w}_{\mathrm{i}}\right)\right]+\left.\lambda \mathrm{Y}_{\mathrm{r}} \mathrm{v}_{\mathrm{i}}^{\prime}\right|_{\mathrm{z}=1, \mathrm{t}}=0, \quad \mathrm{v}_{\mathrm{i}}^{\prime}-\left.\mathrm{S}_{\mathrm{b}} \mathrm{v}_{\mathrm{i}}^{\prime \prime}\right|_{\mathrm{z}=0}=0,\left.\mathrm{v}_{\mathrm{i}}^{\prime \prime}\right|_{\mathrm{z}=1}=0 .
$$

and conditions on $\Theta$ given by Equation (29) and Equation (31) leads to conditions.

$$
\left.\mathrm{w}_{\mathrm{i}}^{\prime}\right|_{\mathrm{z}=1}=0, \quad \mathrm{w}_{\mathrm{i}}-\left.\mathrm{S}_{\mathrm{a}} \mathrm{w}_{\mathrm{i}}^{\prime}\right|_{\mathrm{z}=0}=0 .
$$

Using the above conditions, the coefficients for coordinate functions in the shape function expansion is given by

$$
\begin{gathered}
n_{i}=\left[\left(\frac{p_{i} \pi}{2}\right)^{2} \sin \frac{p_{i} \pi}{2}-\frac{1}{1+S_{b}}\left(\frac{p_{i} \pi}{2}+\sin q_{i}+r_{i} \cos q_{i}\right)\right] /\left[6+\frac{6-3 \alpha}{\alpha\left(1+S_{b}\right)}\right], \\
\mathrm{m}_{\mathrm{i}}=-3 \mathrm{n}_{\mathrm{i}}+\frac{1}{2}\left(\frac{\mathrm{p}_{\mathrm{i}} \pi}{2}\right)^{2} \sin \frac{\mathrm{p}_{\mathrm{i}} \pi}{2} \\
l_{i}=2 S_{b} m_{i}-\frac{p_{i} \pi}{2}
\end{gathered}
$$

with $r_{i}$ and $q_{i}$ determined from the requirement,

$$
\cot q_{i}=r_{i}=S_{a} q_{i} .
$$

It may be noted that setting $S_{a}=0$ in Equation (82), gives $r_{i}=0$ and $q_{i}=\frac{p_{i} \pi}{2}$, which is associated value in the fixed foundation model, case I. Also, by setting $S_{b}=0$ in Equation (81), gives the value of $l_{i}=-\frac{p_{i} \pi}{2}$, reduces to that of case I with the foundation fixed. Thus above coefficients for coordinate functions in the shape function expansion for case II are to be expected.

It was shown that in case II, $r_{i}$ is no longer zero and $q_{i}$ is not in the simple form given by $\frac{p_{i} \pi}{2}$, but is calculated by computing the roots of the Equation (82). The matrix elements needed for the eigenvalue equation in case II is given by Equation (57), Equation (58), Equation (59), Equation (61), Equation (62) and Equation (63), where

$$
\begin{aligned}
& \int_{0}^{1} v_{i}^{\prime \prime} v_{j}^{\prime \prime} d z=4 m_{i} m_{j}+6\left(m_{i} n_{j}+m_{j} n_{i}\right)+12 n_{i} n_{j}-\pi\left(p_{i} m_{j}+p_{j} m_{i}\right)-6\left[n_{i} \sin p_{j} \frac{\pi}{2}+n_{j} \sin p_{j} \frac{\pi}{2}\right]+\delta_{i j} \frac{1}{2}\left[\frac{p_{i} \pi}{2}\right]^{4} \\
& \int_{0}^{1} v_{i}^{\prime} v_{j}^{\prime} d z=l_{i} l_{j}+\left(m_{i} l_{j}+m_{j} l_{i}\right)+\left(n_{i} l_{j}+n_{j} l_{i}\right)+\frac{4}{3} m_{i} m_{j}+\frac{3}{2}\left(m_{i} n_{j}+m_{j} n_{i}\right)+\frac{9}{5} n_{i} n_{j}+ \\
& {\left[l_{i} \sin \frac{P_{j} \pi}{2}+l_{i} \sin \frac{P_{i} \pi}{2}\right]+\frac{4}{\pi}\left\{\frac{m_{i}}{P_{i}}\left[P_{j} \frac{\pi}{2} \sin \left[\frac{P_{j} \pi}{2}\right]-1\right]+\frac{m_{j}}{P_{i}}\left[\sin \left[\frac{P_{i} \pi}{2}\right]-1\right]\right\}+} \\
& \frac{12}{\pi^{2}}\left\{\frac{n_{i}}{P_{j}^{2}}\left[\frac{1}{4} P_{j}^{2} \pi^{2}-2\right] \sin \frac{P_{j} \pi}{2}+\frac{n_{j}}{P_{i}^{2}}\left[\frac{1}{4} P_{i}^{2} \pi^{2}-2\right] \sin \frac{P_{i} \pi}{2}\right\}+\delta_{i j} \frac{1}{2}\left[\frac{P_{i} \pi}{2}\right]^{2}
\end{aligned}
$$




$$
\begin{aligned}
& \int_{0}^{1} v_{i} v_{j} d z=\frac{1}{3} l_{i} l_{j}+\frac{1}{4}\left(m_{i} l_{j}+m_{j} l_{i}\right)+\frac{1}{5}\left(n_{i} l_{j}+n_{j} l_{i}+m_{i} m_{j}\right)+\frac{1}{6}\left(m_{i} n_{j}+m_{j} n_{i}\right)+\frac{1}{7} n_{i} n_{j} \\
& +\left[\frac{2}{\pi}\right]^{2}\left\{\frac{l_{i}}{p_{j}^{2}} \sin \frac{p_{j} \pi}{2}+\frac{l_{j}}{p_{i}^{2}} \sin \frac{p_{i} \pi}{2}\right\}+2\left[\frac{2}{\pi}\right]^{2}\left\{\frac{m_{i}}{p_{j}^{3}}\left[\frac{p_{j} \pi}{2} \sin \left[\frac{p_{j} \pi}{2}\right]-1\right]+\frac{m_{j}}{p_{i}^{3}}\left[\frac{p_{i} \pi}{2} \sin \left[\frac{p_{j} \pi}{2}\right]-1\right]\right\} \\
& +3\left[\frac{2}{\pi}\right]^{4}\left\{\frac{n_{i}}{p_{j}^{4}}\left[\left[\frac{1}{4} p_{i}^{2} \pi^{2}-2\right] \sin \frac{p_{j} \pi}{2}\right]+\frac{n_{j}}{p_{i}^{4}}\left[\left[\frac{1}{4} p_{i}^{2} \pi^{2}-2\right] \sin \frac{p_{i} \pi}{2}\right]\right\}+\frac{1}{2} \delta_{i j} \\
& \int_{0}^{1} w_{j}^{\prime} w_{i}^{\prime} d z=\frac{1+r_{i} r_{j}}{2\left(q_{i}-q_{j}\right)} \sin \left(q_{i}-q_{j}\right)+\frac{1-r_{i} r_{j}}{2\left(q_{i}+q_{j}\right)} \sin \left(q_{i}+q_{j}\right)-\frac{r_{i}-r_{j}}{2\left(q_{i}-q_{j}\right)}\left\{1-\cos \left(q_{i}-q_{j}\right)\right\} \\
& -\frac{r_{i}+r_{j}}{2\left(q_{i}+q_{j}\right)}\left\{1-\cos \left(q_{i}+q_{j}\right)\right\} \\
& \int_{0}^{1} w_{j}^{\prime} w_{i}^{\prime} d z=\frac{1+r_{i}^{2}}{2} q_{i}+\frac{1-r_{i}^{2}}{2} \sin 2 q_{i}-\frac{r_{i}}{2}\left(1-\cos 2 q_{i}\right), \text { for } i=j \\
& \int_{0}^{1} w_{j} w_{i} d z=\frac{1+r_{i} r_{j}}{2\left(q_{i}-q_{j}\right)} \sin \left(q_{i}-q_{j}\right)-\frac{1-r_{i} r_{j}}{2\left(q_{i}+q_{j}\right)} \sin \left(q_{i}+q_{j}\right)-\frac{r_{i}-r_{j}}{2\left(q_{i}-q_{j}\right)}\left\{1-\cos \left(q_{i}-q_{j}\right)\right\} \\
& +\frac{r_{i}+r_{j}}{2\left(q_{i}+q_{j}\right)}\left\{1-\cos \left(q_{i}+q_{j}\right)\right\}, \text { for } i \neq j \\
& \int_{0}^{1} \mathrm{w}_{\mathrm{j}} \mathrm{w}_{\mathrm{i}} \mathrm{dz}=\frac{1+\mathrm{r}_{\mathrm{i}}^{2}}{2} \mathrm{q}_{\mathrm{i}}-\frac{1-\mathrm{r}_{\mathrm{i}}^{2}}{2} \sin 2 \mathrm{q}_{\mathrm{i}}+\frac{\mathrm{r}_{\mathrm{i}}}{2}\left(1-\cos 2 \mathrm{q}_{\mathrm{i}}\right) \text {, for } \mathrm{i}=\mathrm{j} \\
& \int_{0}^{1} v_{i}^{\prime} w_{j} d z=\left\{\frac{l_{i}}{q_{j}} r_{j}+\frac{2 m_{i}}{q_{j}^{2}}\left(1+r_{j} q_{j}\right)+\frac{3 n_{i}}{q_{j}^{3}}\left(2 q_{j}-2 r_{j}+r_{j} q_{j}^{2}\right)\right\} \sin q_{j} \\
& -\left\{\frac{1_{i}}{q_{j}}+\frac{2 m_{i}}{q_{j}^{2}}\left(q_{j}-r_{j}\right)+\frac{3 n_{i}}{q_{j}^{3}}\left(q_{j}^{2}-2\right)-2 r_{j} q_{j}\right\} \cos q_{j}-\left\{\frac{1_{i}}{q_{j}}-\frac{2 m_{i}}{q_{j}^{2}} r_{j}-\frac{6 n_{i}}{q_{j}^{3}}\right\} \\
& -\frac{1}{2} \frac{p_{i} \pi}{2}\left\{\left[\frac{1-\cos \left(\frac{p_{i} \pi}{2}-q_{j}\right)}{\frac{p_{i} \pi}{2}-q_{j}}-\frac{1-\cos \left(\frac{p_{i} \pi}{2}+q_{j}\right)}{\frac{p_{i} \pi}{2}+q_{j}}\right]-r_{j}\left[\frac{\sin \left(\frac{p_{i} \pi}{2}-q_{j}\right)}{\left(\frac{p_{i} \pi}{2}-q_{j}\right)}+\frac{\sin \left(\frac{p_{i} \pi}{2}+q_{j}\right)}{\left(\frac{p_{i} \pi}{2}+q_{j}\right)}\right]\right\} \\
& \left.\mathrm{S}_{\mathrm{b}}\left[\mathrm{v}_{\mathrm{i}} " \mathrm{v}_{\mathrm{j}}^{\prime \prime}\right]\right|_{\mathrm{z}=0}=4 \mathrm{~S}_{\mathrm{b}} \mathrm{m}_{\mathrm{i}} \mathrm{m}_{\mathrm{j}} \\
& \left.\mathrm{S}_{\mathrm{a}}\left[\mathrm{w}_{\mathrm{i}}^{\prime} \mathrm{w}_{\mathrm{j}}^{\prime}\right]\right|_{\mathrm{z}=0}=\mathrm{S}_{\mathrm{a}} \mathrm{q}_{\mathrm{i}} \mathrm{q}_{\mathrm{j}}
\end{aligned}
$$

The integrals provided have been worked out for a particular case and their accuracy is confirmed. Integrals provided by this analysis will give all the matrix elements in both cases. The integrals in case II are identical to those of case $I$ under the limit that gives $r_{i}=0, S_{a}=0, S_{b}=0$ and $q_{i}=\frac{p_{i} \pi}{2}$, for all $i=1,2, \ldots, n$. The eigenvalue equations may now be constructed for both cases and their solution given by standard matrix eigenvalue calculations.

\section{Summary and Conclusion}

In this paper, a variational approach (Hamilton's principle) is used to develop the equations of motion for coupled shear walls on both fixed and flexible base. It is shown that the equations of motion developed for fixed 
base using Hamilton's principle is consistent with the sixth order differential equation developed by Mukherjee and Coull. Boundary conditions for both fixed and flexible base are developed. The approach used in this paper to develop equations of motion and boundary conditions is different from that of Mukherjee and Coull. Also Mukherjee and Coull's dynamic analysis considers only the free vibration problem and did not address the dynamic response of the structure under loading. The developed equations of motion in both cases are a fourth order and second order differential equations, which gives ease to solve them by hand calculations. External load applied to the coupled shear wall system can be taken into account by using the developed equations of motion. By setting the external load, $p(x, t)$, equal to zero, free vibration problem can be analyzed.

By using the equations of motion and the associated boundary conditions an approximation technique, the Ritz-Galerkin method, was used to develop eigenvalue equations. These matrix eigenvalue equations developed, can be useful to compute mode shapes and eigenvalues for any degrees-of-freedom desired for increased accuracy. The matrix coefficients computed are in good agreement with integral values provided by Mukherjee and Coull (1974) for case I. For case II, integral values developed were significantly different due to $r_{i} \neq 0, q_{i}$ have different set of roots. This significant difference is due to consideration of external load on coupled shear wall system while developing equations of motion. In some, this paper provides all the theoretical development needed to model coupled shear walls with an external load applied.

\section{References}

Beck, H. (1962). Contributions to the analysis of coupled shear walls. J. ACI., 59(8), 1055-1069.

Chitty, L. (1947). On the cantilever composed of a series of parallel beams interconnected by cross bars. Phil. Mag., 38.

Chitty, L., \& Wan, W. Y. (1948). Tall building structures under wind load. Proc. 7th Int. Congr. Appl. Mech., 1(23), 254-268.

Coull, A., \& Choudhury, J. R. (1967). Stresses and Deflections in coupled shear wall. J. Am. Concr. Inst., 65-72.

Gluck, J. (1973). Elasto-Plastic analysis of coupled shear walls. J. Struct. Engr. ASCE, 99(ST8), 1743-1759.

Kuang, J. S., \& Chau, C. K. (1996). Dynamic analysis of stiffened coupled shear walls. 11th World conf. on Earthquake Eng., paper No. 1964. Retrieved from http://www.iitk.ac.in/nicee/wcee/article/11_1964.PDF

Kuang, J. S., \& Chau, C. K. (1999). Dynamic behavior of stiffened coupled shear walls with flexible base. Comput. Struct., 73, 327-339. http://dx.doi.org/10.1016/S0045-7949(98)00261-2

Li, G. Q., \& Choo, B. S. (1995). Natural frequency evaluation of coupled shear walls. Struct. Engr., 73, 301-304.

Mukherjee, P. R., \& Coull, A. (1973). Free vibrations of coupled shear walls. Earthquake Eng. Struct. Dyn., 1, 377-386. http://dx.doi.org/10.1002/eqe. 4290010408

Mukherjee, P. R., \& Coull, A. (1974). Free vibrations of coupled shear walls on flexible base. Proc. Instn. Civ. Engrs., 2(57), 493-511. http://dx.doi.org/10.1680/iicep.1974.4028

Rosman, R. (1964). Approximate analysis of shear walls subjected to lateral loads. J. Am. Concr. Inst., 61(6), 717-732.

Skattum, K. S. (1971). Dynamic analysis of coupled shear walls and sandwich beams. Earthquake Eng. Res. Lab., California Inst. of Technol., Pasadena, CA.

Tso, W. K., \& Biswas, J. K. (1973). General analysis of nonplanar coupled shear walls. Proc. Of ASCE, 99(ST3), 365-380.

Wang, Q., \& Wang, L. Y. (2005). Estimating periods of vibration of buildings with coupled shear walls. J. Struct. Eng., 131(12), 1931-35. http://dx.doi.org/10.1061/(ASCE)0733-9445(2005)131:12(1931)

\section{Appendix A: List of Symbols}

A Total area of shear walls

$A_{1}, A_{2} \quad$ Area of shear walls 1 and 2

$A_{f_{1}}, A_{f_{2}} \quad$ Area of foundations 1 and 2

a Length of connecting beams

$\alpha^{\prime} \quad$ Coefficients in static differential equation of motion 


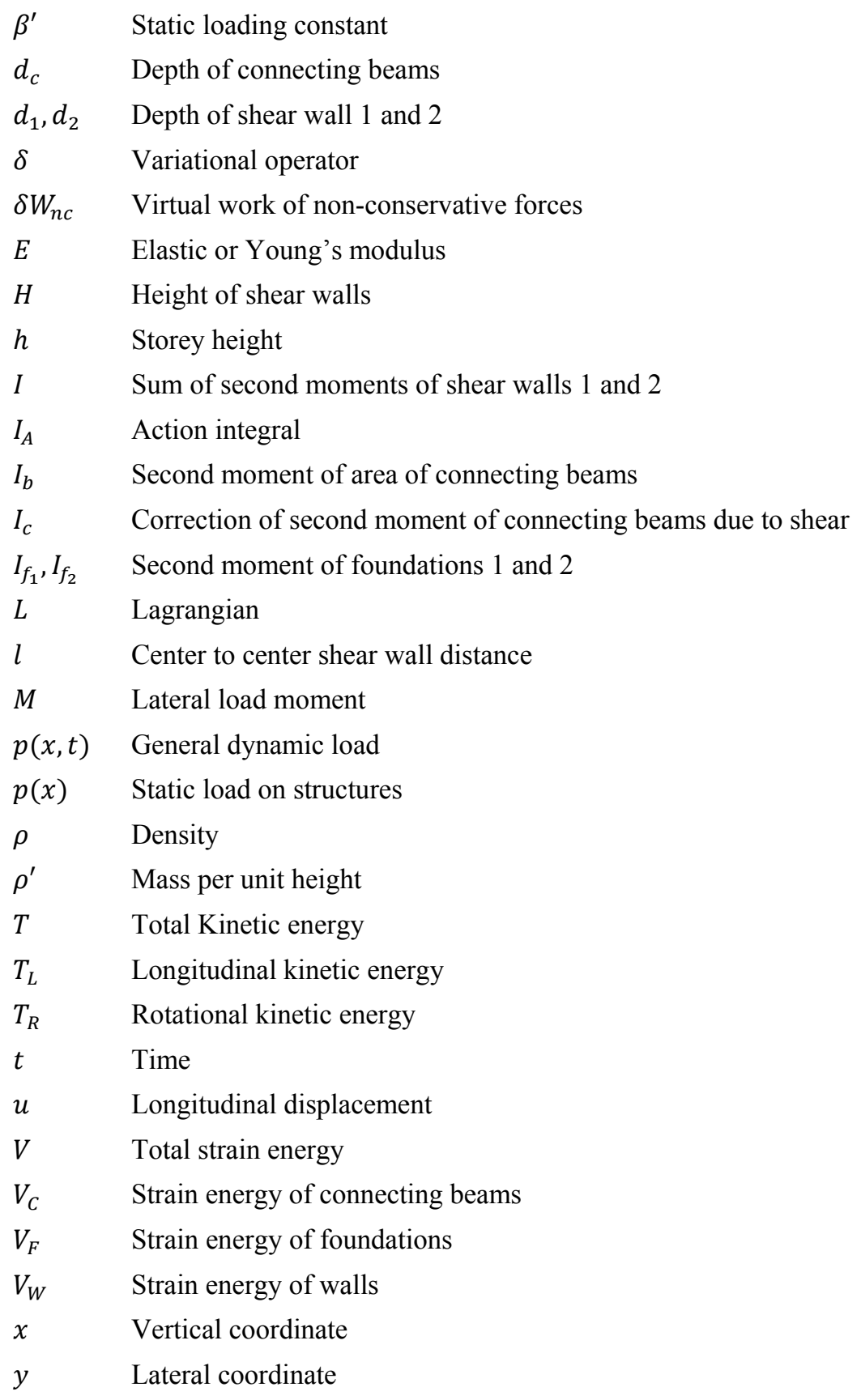

